\title{
Epigenetics and phenotypic variation in mammals
}

\author{
Anne E. Peaston, ${ }^{1 \star}$ Emma Whitelaw $^{2}$ \\ ${ }^{1}$ School of Molecular and Microbial Biosciences, The University of Sydney, New South Wales 2006, Australia \\ ${ }^{2}$ Division of Population Studies and Human Genetics, Queensland Institute of Medical Research, Royal Brisbane Hospital, \\ Queensland 4029, Australia
}

Received: 14 December 2005 / Accepted: 2 February 2006

\begin{abstract}
What causes phenotypic variation? By now it is clear that phenotype is a result of the interaction between genotype and environment, in addition to variation not readily attributable to either. Epigenetic phenomena associated with phenotypic variation at the biochemical, cellular, tissue, and organism level are now well recognized and are likely to contribute to the "intangible variation" alluded to. While it is clear that epigenetic modifications are mitotically heritable, the fidelity of this process is not well understood. Inheritance through more than one generation of meioses is even less well studied. So it remains unclear to what extent epigenetic changes contribute to phenotypic variation in natural populations. How might such evidence be obtained? What are the features of phenotypes that might suggest an epigenetic component? How much of the epigenetic component is truly independent of genetic changes? The answers to such questions must come from studies designed specifically to detect subtle, stochastically determined phenotypic variation in suitable animal models.
\end{abstract}

\section{Introduction}

The phenotype-driven genetics methods of linkage analysis and positional cloning have enabled us to discover the genetic cause of mammalian Mendelian phenotypes, that is, those phenotypes with a perfect correspondence between phenotype and a single-

\footnotetext{
${ }^{\star}$ Present address: The Jackson Laboratory, 600 Main Street, Bar Harbor, ME 04609, USA

Correspondence to: Anne E. Peaston; E-mail: anne.peaston@jax.org
}

locus genotype, (Risch 2000; van De Sluis et al. 2002). However, much mammalian phenotypic variance cannot be attributed to single-gene effects, and other sources include multigene effects, environmental influences, noise, and epigenetic effects. Epigenetic effects are those effects caused by chemical modifications to DNA that do not alter the DNA sequence but do alter the probability of gene transcription. Such modifications include direct covalent modification of the DNA by methylation of cytosines in symmetric or asymmetric contexts and modification of the proteins that bind to DNA. Such modifications may alter DNA accessibility to transcription complexes at a local level and affect higherorder chromatin structure at regional and genomewide levels, thus linking genome structure and transcriptional regulation. The progressive elucidation of epigenetic molecular mechanisms in different organisms has been and continues to be a major project of many laboratories. Excellent reviews on this topic appear frequently, reflecting the rapid advances of knowledge in the field and its entanglement with the new field of small RNAs (Almeida and Allshire 2005; Bannister and Kouzarides 2005; Bernstein and Allis 2005; Mellor 2005; Sproul et al. 2005; Zamore and Haley 2005; Zilberman and Henikoff 2005) (the reader is also referred to Symposium 69, 2004, of the Cold Spring Harbor Symposia on Quantitative Biology, containing diverse epigenetics reviews).

Of special relevance to the mammalian genome, phenotype-driven genetics methods such as sensitized mouse mutagenesis studies are discovering molecules involved in mammalian epigenetic regulation and are exposing subtle effects of such molecules on the whole animal (Blewitt et al. 2005; Bultman et al. 2005). Strategies used to study epigenetic mechanisms in the mouse have recently been well reviewed (Mager and Bartolomei 2005). This review does not focus on epigenetic mecha- 
nisms but takes up the topic of the biological significance of epigenetic genome regulation, focusing on mammals as much as possible.

Epigenetic mechanisms are intimately involved in setting up and maintaining the two major forms of chromosomal structure, heterochromatin and euchromatin, and in the structural switches of facultative heterochromatin between the two. Nuclear transplantation studies and studies of germ cell formation have established that epigenetic reprogramming is an essential component of the very earliest stages of mammalian embryogenesis, and in Drosophila of germ cell development and maintenance (Hochedlinger and Jaenisch 2002; Xi and Xie 2005). Disruption of normal epigenetic reprogramming, like that which occurs following interference with normal DNA methylation processes, has severe impacts on development of the embryo (Li 2002; Li et al. 1992; Okano et al. 1999|. Spontaneous epigenetic pathology has been linked with several sorts of human disease, e.g., imprinting disorders and cancer (Egger et al. 2004; Holm et al. 2005).

The cardinal signs of epigenetic effects on gene transcription are variable expression of a gene in a population of isogenic individuals (variable expressivity) and/or a mosaic pattern among cells of the same type within an individual (variegation) (Whitelaw and Martin 2001 and references therein). The phrase "metastable epialleles" was coined to describe alleles with more than one stable epigenetic state driving variable expressivity and variegation (Rakyan et al. 2002). At each new generation, the establishment of a metastable epiallele's epigenetic state is probabilistic, although there may be some parental influence, and once established the epigenetic state is mitotically inherited. Thus, classical imprinted alleles are epialleles, but they are not metastable epialleles because establishment of their epigenetic state in each new generation is strictly determined by the parent of origin of the allele. Epigenetic states at chromosomal loci are reversible and changes of epigenetic state occur regularly during development as cells undergo differentiation and are age-dependent in the adult animal (BennettBaker et al. 2003). Over the lifespan of the animal, it was estimated that epigenetic changes occur more frequently than DNA mutations (Bennett-Baker et al. 2003).

Using a proviral construct transfected into mammalian cells, Lorincz et al. (2002) showed that the construct's DNA methylation state was established stochastically. The state established was influenced by the initial methylation density and by a cis-acting regulatory element whose absence increased the probability of methylation of the construct. Unmethylated or densely methylated constructs were stably maintained and propagated, while low-density methylated constructs were inherently unstable and subject to stochastic demethylation or de novo methylation (Lorincz et al. 2002). Stochastic establishment of methylation of naturally occurring alleles has been observed in mice and is believed to be a general feature of DNA cytosine methylation in mammals.

There is no doubt that epigenetic modifications to DNA are mitotically heritable, and there is welldocumented evidence of meiotic or transgenerational epigenetic inheritance for individual genes over several generations in a number of model organisms including flies, mice, worms, and plants (Finnegan 2002; Rakyan et al. 2003; Zilberman and Henikoff 2005). But how much phenotypic variability does the epigenotype account for in mammals and to what extent does transgenerational epigenetic inheritance occur in natural populations?

\section{Epigenetics and phenotypic variation}

The extent to which epigenotype contributes to variable phenotype is somewhat controversial and is difficult to disentangle from genetic and environmental contributions in outbred natural populations. Much evidence is indirect, being the genetic equivalent of an artwork's "negative space," i.e., epigenetic effect is a strong candidate source of phenotype variability after genetic and environmental effects have been ruled out. For example, animal studies using isogenic mammalian populations in defined environments showed that approximately $70 \%-80 \%$ of phenotype "random variability" in biological quantitative traits was unrelated to environment (Gartner 1990). At the time, technical and perhaps conceptual limitations prevented better definition of the source of this apparently nongenetic, nonenvironmental variation. In a number of instances, phenotypic discordance between human monozygotic (MZ) twins raised apart is no greater than phenotypic discordance of $\mathrm{MZ}$ twins raised together. This suggests that a large proportion of the discordance is a result of something other than environment (Wong et al. 2005). Indeed epigenetic discordance can account for phenotypic discordance between MZ twins in imprinting disorders such as Beckwith-Wiedemann syndrome (Weksberg et al. 2003).

More recently, gene transcription has been directly investigated as a quantitative trait in studies of phenotypic variability. Do these studies tell us anything about the role of epigenetics in the determination of phenotype? Epigenetic modifiers of a notional locus A might be identified as cis-acting, 
without DNA sequence changes in the "mutant" allele. As sensitized mutagenesis studies have shown, trans-acting loci may also be identified, e.g., loci encoding histone or DNA methyltransferases. Microarray-based global transcription profiling studies in combination with classical genetic studies, such as linkage analysis in human and mouse populations and other model organisms such as yeast, show that natural variation in transcript abundance is common in eukaryotes and is often genetically linked to multiple loci. Mouse and human studies indicate that cis-acting elements are an important component of mammalian gene expression variability, although the sensitivity of microarray platforms to detect cis-acting elements in diploid organisms is limited by the inability to separate allele-specific measurements (Stamatoyannopoulos 2004).

The involvement of cis-acting elements in transcript abundance implicates genetic involvement of regulatory systems involved in epigenetic effects such as promoters, silencers, enhancers, and insulators. Indeed, allele-specific transcriptional variation in 4 of 69 mouse genes expressed from four different inbred strains was accompanied by multiple strain-specific promoter sequence differences for each gene (Cowles et al. 2002). In this case, the results indicate a likely genetic rather than epigenetic source of the variation, as do studies showing Mendelian inheritance of allele-specific expression variation in humans (Yan et al. 2002). Incomplete penetrance was observed in another similar study, suggesting a role for epigenetic factors, but the influence of trans factors could not be ruled out (Pastinen et al. 2004). As with other quantitative traits, variance in gene expression between $\mathrm{MZ}$ twins, e.g., as found by Cheung et al (2003) and Sharma et al (2005), more clearly suggests a distinct role for epigenetic phenomena.

Genome-scale transcriptional profiling studies and allelic expression patterns also identify considerable variation lacking an obvious genetic source (Brem et al. 2002; Cheung et al. 2003; Schadt et al. 2003). However, tracking down a source as purely epigenetic is severely limited if not impossible when working with outbred populations because of the abundant supply of genetic variation and the difficulties in controlling confounding factors such as environment or allelic transcript stability. Furthermore, the intent of most studies is to quantify genetic causes of gene expression variation between tissues, individuals, or populations. Thus, the study designs will not be sensitive detectors of epigenetic effects, despite showing there is potential for widespread epigenetic regulation of gene expression. It may be possible to gain an idea of the genome-wide impact of epigenetic transcriptional effects by transcriptional profiling studies within inbred strains of animals, under defined environmental conditions.

\section{Epigenomics}

Epigenomics has been defined as the study of the effects of structural and chemical modifications to chromatin and its component proteins and DNA (Murrell et al. 2005). The epigenome changes according to cell cycle, cell type, age of the organism, and species, and in response to environmental factors such as nutrition. Nonetheless, with increasing awareness of the importance of epigenetic mechanisms in human disease, several groups have set out to characterize mouse and human epigenomes. Technologies used for genomic analysis of DNA methylation, chromatin-associated proteins, and chromatin higher-order structures were recently reviewed and are not discussed in detail here (Murrell et al. 2005). Recent studies marrying epigenome analysis with gene expression are confirming that epigenetic variation is rife within mammalian genomes, at least within the mouse and human.

The Human Epigenome Project (HEP) aims to "identify, catalogue and interpret genome-wide DNA methylation patterns and profiles of all human genes in all major tissues" and their diseased variants (Murrell et al. 2005). Bisulfite sequencing remains the most sensitive and specific method for analyzing DNA methylation, although development of new genome-scale methods may eventually rival it and provide potential for higher throughput analysis (Murrell et al. 2005). In a pilot study, HEP used a modified high-throughput bisulfite sequencing method and also matrix-assisted laser desorption/ ionisation mass spectrometry (MALDI-MS) to analyze cytosine methylation of $\mathrm{CpG}$ dinucleotides in targeted regions of 90 major histocompatibility (MHC) region genes, sampling six different tissue types from 32 persons (Rakyan et al. 2004). The two methods produced comparable results and showed that there was considerable interindividual variation in DNA methylation, with over $80 \%$ of unique CpG sites showing greater than $20 \%$ variation between individuals. Methylation patterns of about $10 \%$ of amplicons were tissue specific. Moreover, CpG methylation status of the upstream sequence of a subset of 24 genes correlated with their expression levels in prostate and liver. In principle, this confirms, at the genomic level in a natural population, the general model that epigenetic states influence phenotype, i.e., gene expression, and that epigenetic variation due to DNA methylation is common in the 
genome, at least in the human MHC. As Rakyan et al. point out, problems remain with inherent technical variation and the use of samples uncontrolled for factors affecting epigenetic state such as environment, age and gender. Moreover, the use of genetically diverse samples leaves open the possibility that certain genotypes might be associated with a particular epigenotype.

Combined chromatin immunoprecipitation (ChIP) and microarray studies have been used to construct genome-wide maps of modified histones in flies and yeast (Bernstein et al. 2002; Pokholok et al. 2005; Schubeler et al. 2004). These studies showed that the transcribed parts of active genes are associated with histone $\mathrm{H} 3$ lysine 4 (H3K4) methylation. To better delineate the properties of mammalian chromatin on a large scale, Bernstein and colleagues (2005) used a combination of ChIP, linear DNA amplification, and tiling oligonucleotide arrays to map histone modifications for human Chromosomes 21 and 22 in HepG2 hepatoma cells, and for six genomic loci orthologous in mouse and human. An interesting finding from this study was that conservation of histone modifications between orthologs in human and mouse was stronger than conservation of DNA sequence.

In a different approach, ChIP and reverse-transcription real-time PCR was used to assess histone lysine methylation states at DNA repeats in mouse embryonic cells and their differentiated derivatives (Martens et al. 2005). This study showed that in major and minor satellite repeats, the repressive histone marks-trimethylation of histone H3 lysine 9 and histone H4 lysine 20-appeared stable between different cell types. Conversely, for other classes of repeats such as DNA transposons and retrotransposons, repressive histone lysine methylation states varied between cell types. Some marks appeared quite variable within a cell and repeat type, suggesting the potential for variable transcriptional repression.

\section{Epigenetic studies in isogenic populations}

In an attempt to link epigenetic variation with phenotypic discordance in MZ twins, gene expression at the genomic scale has also been studied using a large group of MZ twins (Fraga et al. 2005). Global and locus-specific 5mC DNA methylation, and acetylation of histones 3 and 4 were analyzed in lymphocytes of 15 male and 25 female MZ twin sets. The results showed that $65 \%$ of twins had almost identical epigenetic characteristics but that $35 \%$ had divergent characteristics and that the widest divergence was seen in older twins and those with divergent lifestyles. Microarray analysis of gene expression appeared to confirm these findings. The essential point of this article is that it shows that epigenetic differences between individuals correlate with gene expression differences in the presence of the same genetic background. Discordance between MZ twins with respect to occurrence of schizophrenia led to attempts to attribute this to epigenetic variation. Petronis et al. (2003), using evidence from two pairs of twins, one pair being discordant for schizophrenia, claimed proof of principle that multiple epigenetic differences exist between $\mathrm{MZ}$ twins (Petronis et al. 2003). The study analyzed the promoter region of a single gene with methods rarely used by others; thus, the conclusions await independent confirmation.

It is likely that further twin studies, as well as studies in isogenic mice, will expand our understanding of the association between epigenetics and phenotype in mammals. For example, studies of gene expression in large sets of MZ twins, ideally discordant for some phenotypic character such as a genetically determined incompletely penetrant disease, could provide the groundwork for further studies to link epigenotype to gene expression and/or biological phenotype.

\section{Transgenerational epigenetic inheritance}

With accumulating evidence of epigenetic association with normal phenotypic variation, the question arises as to the heritability of epigenetic characteristics. Transgenerational epigenetic inheritance is difficult to study in outbred populations because the effects are stochastic, may be parentally influenced, and may be quite small, requiring large study populations to detect. As noted elsewhere, transgenerational epigenetic inheritance does not include imprinting, although this strict exclusion may not apply in some cases (see discussion about Kaati et al. below) (Rakyan and Whitelaw 2003). While transgenerational epigenetic inheritance has been documented in many eukaryotes, evidence in mammals is scanty. Abnormal methylation patterns of mouse urinary protein inherited for two generations after nuclear transfer were reported by Roemer et al. (1997). However, other reports indicate reversal of abnormal clone phenotypes in offspring of clones from nuclear transplantation, suggesting that the abnormalities were epigenetic in nature and were corrected in the germ cells of the clone (Wells 2005).

Epigenetic inheritance has been studied extensively in viable yellow mice $\left(A^{v y}\right)$ and Axin-fused $\left(A x i n^{F u}\right)$ mice (Morgan et al. 1999; Rakyan et al. 2003). In these mice, a variably penetrant phenotype 
is linked to the activity and DNA methylation status of a retrotransposon driving abnormal expression of the $A^{v y}$ gene and production of aberrant transcripts from the $A x i n^{F u}$ gene. The studies show that transgenerational inheritance of the methylation mark at these alleles can be through the maternal and/or the paternal germline, and it is strain dependent.

These two mouse models are convenient for investigation of epigenetic inheritance in that a clear phenotype is linked to an epigenetically controlled promoter for both genes. It is logical to suppose that many other examples exist with either a similar class of alternative promoter (i.e., retrotransposon promoter) or a more standard promoter; however, their detection and investigation is problematic if they lack a distinct phenotype. For example, a third naturally occurring metastable epiallele is the $C a b p^{I A P}$ allele, discovered by searching gene expression databases for genes with alternative $5^{\prime}$ regions provided by an endogenous retrovirus (Druker et al. 2004). No obvious phenotype, other than aberrant transcripts, has been associated with $\mathrm{Capb}^{I A P}$ and its epigenetic heritability status has not been studied.

\section{Epigenetic inheritance of environmentally induced phenotypes}

An important idea driving interest in epigenetic inheritance is whether environmentally induced changes in epigenetic status, and hence gene transcription and phenotype, can be transmitted through more than one generation. $A^{v y}$ mice were used to demonstrate that maternal diet influences epigenetic states and hence phenotypes of $F_{1}$ offspring through altering the probability of methylation of the $A^{\text {vy }}$ locus (Waterland and Jirtle 2003; Wolff et al. 1998). However, the experiments in these two studies did not test whether the altered epigenetic states were then passed, without further dietary interference, to subsequent generations, and so no further inferences can be drawn regarding heritability of environmentally mediated epigenetic effects.

An intriguing link was made in rats between the quality of maternal care as measured by licking and nursing behavior and the epigenetic status of the glucocorticoid receptor gene and behavioral phenotype of the offspring (Weaver et al. 2004). Again, the study was conducted on too few generations to determine whether the effects might be heritable. Offspring of male mice treated with chromium(III) chloride have an altered lifetime risk of developing specific cancers, and Shiao and colleagues hypothesized an epigenetic rather than a genetic cause (Shiao et al. 2005 and refs therein). Evidence supporting the argument included allele-specific DNA hypomethylation of the ribosomal RNA spacer promoter of the $45 \mathrm{~S}$ ribosomal RNA gene in the sperm of treated mice. In addition, the paternally acquired epimutation is transmitted to the $F_{1}$ offspring (Y.H. Shiao, personal communication), but the work awaits further clarification through linkage of $45 \mathrm{~S}$ ribosomal RNA hypomethylation to the phenotype and study of the phenotype in the $\mathrm{F}_{2}$ generation.

Transgenerational effects of environmental exposure to hormones or hormone-like substances has been of longstanding interest to the medical and ecologic communities. Diethylstilbestrol (DES), for example, was shown to affect the cancer susceptibility phenotype of "grandchildren" of DES-exposed female mice; the results suggested transmission of epigenetic pathology, but epigenetic investigations were not reported (Newbold et al. 2000). A transgenerational epigenetic modification affecting at least three subsequent generations has been reported for rats exposed in utero to vinclozolin, an agricultural fungicide, or methoxychlor, a pesticide (Anway et al. 2005). Metabolites of these agents possess weak endocrine activity, and the agents are known generically as endocrine disruptors. Earlier experiments showed that either agent, when administered to the female mice or rats in midgestation, during embryonic primordial germ cell migration and gondadal sex determination, produced defective spermatogenic capacity in $\mathrm{F}_{1}$ offspring (Shimamura et al. 2002; Uzumcu et al. 2004). The underlying hypothesis of the new work is that disruption of normal genome demethylation and remethylation in primordial germ cells of the embryo $\left(F_{1}\right)$ leads to a change in the potential for normal demethylation and remethylation of the affected loci in the following and subsequent generations $\left(\mathrm{F}_{2}+\right)$. The abnormal male phenotypes were observed in several male lines each from differently treated $\mathrm{F}_{0}$ dams (and presumably different sires) of two different rat strains. This, and the non-Mendelian inheritance of the traits, argue against the possibility of a vinclozolin-induced genetic cause for the phenotype, and together with the methylation data suggest epigenetic inheritance. It will be interesting to follow the future course of these studies as the nature of the epigenetic abnormalities is explored in more depth.

\section{Human epigenetic inheritance}

Recently, germline epimutations of $M L H 1$ have been identified in individuals with colorectal and other cancers characterized by microsatellite instability (Hitchins et al. 2005; Suter et al. 2004). MLH1 encodes a protein involved in DNA mismatch repair, 
and somatic biallelic hypermethylation of its promoter is associated with sporadic colorectal carcinoma in older women. Heterozygous germline mutations of $M L H 1$ cause the autosomal dominant cancer predisposition syndrome hereditary nonpolyposis colorectal cancer (HNPCC). Promoter methylation screens of several genes, including $M L H 1$, were conducted in individuals with personal or family histories of colorectal cancer, but lacking evidence of $M L H 1$ mutation. Three individuals were identified with hemiallelic promoter hypermethylation of MLH1 in tissues from all embryonic germ cell lineages. The affected allele was silenced; loss of the other allele was shown in tumor tissue, and absence of MLH1 protein in tumors demonstrated complete functional loss of $M L H 1$. A low proportion (1\%) of carrier sperm in one of the three probands suggested potential for transgenerational inheritance of the allele, but it also demonstrated that the epimutation was unstable in the germline, having been erased during gametogenesis in most sperm. There was no evidence of the epimutations in parents or siblings of the probands, and the daughter of one proband inherited his $M L H 1$ allele but with normal methylation. Although the evidence is insufficient to rule out transgenerational inheritance of the MLH1 epimutation, it suggests that inheritance of this epimutation is likely to be weak, if it occurs at all.

A major environmental factor affecting human health is nutrition, and many populations today and in the past have been exposed to alternating feast or famine conditions. Maternal nutrition during pregnancy can influence the disease susceptibility phenotype of children, and can influence, through the female line, the birthweight of grandchildren (Lumey and Stein 1997). In order to study the effects of grandparental nutrition on cardiovascular mortality and the incidence of diabetes, Kaati et al. (2002) analyzed the records of three generations of people in an isolated area of northern Sweden. The authors had previously shown that longevity was inversely related to energy intake of the grandfather during his slow growth period in childhood (Bygren et al. 2000). In the new study, the original study group was expanded to include 239 individuals born in either 1890, 1905, or 1920 (Kaati et al. 2002). The study analyzed the relationship to cardiovascular mortality or diabetes of food availability during the parents' and grandparents' childhood slow growth period (9-12 years for boys, $8-10$ years for girls). The results showed that poor paternal or good maternal food availability protected against cardiovascular mortality, while good paternal food availability tended to protect from diabetes. Poor paternal grandfather's food availability tended to protect from diabetes and, as previously shown, increased longevity, whereas good paternal grandfather's food availability predisposed to diabetes. The size of probands' sibships was increased if the paternal grandfather was exposed to food shortages or if the father was exposed to a food surfeit. The findings are important because they show the effects of nutrition on one generation can reach forward through the male line across at least two generations. The opposing effects of paternal and grandpaternal nutrition suggest that effects are reversible. A genetic mechanism for transgenerational transmission of the nutrition effects was deemed unlikely in the absence of evidence for intense selection across the three study generations. Kaati et al. (2002) hypothesized an epigenetic cause, most likely affecting an imprinted gene, and nominated the variable number tandem repeat (VNTR) minisatellite upstream of the INS-IGF2-H19 imprinted region as a candidate locus for the effect. The region is paternally imprinted and paternal variation at the INS VNTR had been associated with altered risk of type 2 diabetes, thus suggesting that factors affecting an imprinted gene might influence the pathogenesis of type 2 diabetes (Huxtable et al. 2000).

Pembrey (2002) speculated that the mechanism for transgenerational responses to nutrition observed in the Kaati et al. study primarily could be related to reproduction. The period of slow growth during boyhood coincides with the onset of spermatogonial differentiation and spermatocyte production, and consequently the remethylation of marks erased during gametogenesis at loci such as at the imprinting control region between IGF2 and H19 (Kerjean et al. 2000; Pembrey 2002). Therefore, during this period of dynamic epigenetic events in the testis, nutrition could potentially directly affect imprint establishment, and such an altered mark might be heritable over several generations or susceptible to reversal in the following generation, depending on nutritional exposures. If this were true, then perhaps the notion of imprinting, at least for this locus, would need to be revised to include some flavor of a metastable epiallele in which stochastic variation was prompted by environmental exposure during a sensitive period. It should be noted that the effect of the INS VNTR on susceptibilty to type 2 diabetes is controversial, with at least two recent large studies coming to opposite conclusions (Bennett et al. 2005; Meigs et al. 2005).

\section{Underlying genetic instability could be a confounding effect}

From the preceding sections it is evident that the scientific community is still at the very edge of 
understanding the impact of epigenetics on phenotypic variation. In outbred populations, recombination and the existence of innumerable SNPs could theoretically alter epigenetic regulation of genes by altering the potential for DNA methylation and chromatin-associated protein attachment to loci. Further complicating this is the recent realization of extensive large-scale and fine-scale structural variation in mouse and human genomes (Crawford et al. 2004; Iafrate et al. 2004; McVean et al. 2004; Myers et al. 2005; Sebat et al. 2004; Tuzun et al. 2005). This variation includes deletions, inversions, insertions, copy-number variation, and duplication of large genome segments. Over 25,000 recombination hotspots were recently identified in the human genome, occurring preferentially within $50 \mathrm{~kb}$ of genes and not within transcribed domains (Myers et al. 2005). Structural variation has been identified as the source of phenotypic variation mediating human response to the environment, proof of principle that structural variation is important in human biology (Gonzalez et al. 2005). It is not known what effect this might have on regulatory sequences subject to epigenetic control, and it could be argued that structural changes leading to altered epigenetic regulation of genes are at heart a genetic cause of variation. However, this problem remains theoretical in the absence of a deeper understanding of the epigenome and its behavior. It is interesting to note that naturally occurring transgenerational epigenetic inheritance in plants occurs at repeat sequences or at repeat arrays of transgenes (Zilberman and Henikoff 2005). Perhaps, in mammalian genomes, other repeat types, in addition to the known retrotransposon examples, might also be reasonable candidates for epigenetic modification and transgenerational inheritance.

An important question stemming from the investigation of epigenetic heritability is can epigenotype be selected in an evolutionary sense? Data from the plant world suggest that epigenetically determined phenotypic variability allows plants to respond rapidly to environmental change, potentially allowing survival and reproduction until genetic change can provide more stable adaptation or until the environment reverts to the previous state (Finnegan 2002). The mouse and human data presented here are not really able to address this idea. What sort of data might be compatible with the notion of evolutionary selection of an epigenetically determined variation? An intriguing observation of heritable phenotypic plasticity in birds provides clues as to the sort of study that might provide insight into epigenetic inheritance and selection (Nussey et al. 2005). Nussey and colleagues analyzed the variability in reproductive timing in a population of great tits, Parus major, across 30 generations in the wild. Reproductive timing in these birds is highly plastic in response to spring temperatures, with signficant variation between birds in the plasticity of the response. Coincident with changes in climate and food availability over the observation period, selection as measured by lifetime reproductive success has favored more plastic birds who are better able to synchronize egg laying with climate and hence food availability.

\section{Concluding remarks}

Transgenerational epigenetic inheritance of phenotype is the flavor of the month and is provoking much interesting discussion (Jablonka and Lamb 2005), but little hard data support it in mammals. In the same way as maternal effects can be mistaken for genetic effects unless explicitly modeled (Kruuk 2004 and references therein), it is possible that epigenetic effects require specific modeling for detection. More sophisticated large studies are needed in outbred populations, looking at the right sort of phenotype, ideally a phenotype with known genetic input, enabling elimination of a genetic cause for the phenotypic variation. Inbred model populations are still relatively untapped as an experimental resource for investigating transgenerational epigenetic inheritance. As mechanisms are better understood and population studies proceed, interesting findings are bound to emerge.

\section{Acknowledgments}

This work was supported by CJ Martin Fellowship 007150 awarded by the NHMRC of Australia (AEP) and by NHMRC project grants (EW). The authors thank the anonymous reviewers for their thoughtful comments.

\section{References}

1. Almeida R, Allshire RC (2005) RNA silencing and genome regulation. Trends Cell Biol 15, 251-258

2. Anway MD, Cupp AS, Uzumcu M, Skinner MK (2005) Epigenetic transgenerational actions of endocrine disruptors and male fertility. Science 308, 1466-1469

3. Bannister AJ, Kouzarides $\mathrm{T}$ (2005) Reversing histone methylation. Nature 436, 1103-1106

4. Bennett A, Sovio U, Ruokonen A, Martikainen $\mathrm{H}$, Pouta A, et al. (2005) No association between insulin gene variation and adult metabolic phenotypes in a large Finnish birth cohort. Diabetologia 48, $886-8891$ 
5. Bennett-Baker PE, Wilkowski J, Burke DT (2003) Ageassociated activation of epigenetically repressed genes in the mouse. Genetics 165, 2055-2062

6. Bernstein BE, Humphrey EL, Erlich RL, Schneider R, Bouman P, et al. (2002) Methylation of histone H3 Lys 4 in coding regions of active genes. Proc Natl Acad Sci USA 99, 8695-8700

7. Bernstein BE, Kamal M, Lindblad-Toh K, Bekiranov S, Bailey DK, et al. (2005) Genomic maps and comparative analysis of histone modifications in human and mouse. Cell 120, 169-181

8. Bernstein E, Allis CD (2005) RNA meets chromatin. Genes Dev 19, 1635-1655

9. Blewitt ME, Vickaryous NK, Hemley SJ, Ashe A, Bruxner TJ, et al. (2005) An N-ethyl-N-nitrosourea screen for genes involved in variegation in the mouse. Proc Natl Acad Sci USA 102, 7629-7634

10. Brem RB, Yvert G, Clinton R, Kruglyak L (2002) Genetic dissection of transcriptional regulation in budding yeast. Science 296, 752-755

11. Bultman SJ, Gebuhr TC, Magnuson T (2005) A Brg1 mutation that uncouples ATPase activity from chromatin remodeling reveals an essential role for SWI/ SNF-related complexes in $\beta$-globin expression and erythroid development. Genes Dev 19, 2849-2861

12. Bygren LO, Edvinsson S, Brostrom G (2000) Change in food availability during pregnancy: Is it related to adult sudden death from cerebro- and cardiovascular disease in offspring? Am J Human Biol 12, 447-453

13. Cheung VG, Conlin LK, Weber TM, Arcaro M, Jen KY, et al. (2003) Natural variation in human gene expression assessed in lymphoblastoid cells. Nat Genet 33 $422-425$

14. Cowles CR, Hirschhorn JN, Altshuler D, Lander ES (2002) Detection of regulatory variation in mouse genes. Nat Genet 32, 432-437

15. Crawford DC, Bhangale T, Li N, Hellenthal G, Rieder MJ, et al. (2004) Evidence for substantial fine-scale variation in recombination rates across the human genome. Nat Genet 36, 700-706

16. Druker R, Bruxner TJ, Lehrbach NJ, Whitelaw E (2004) Complex patterns of transcription at the insertion site of a retrotransposon in the mouse. Nucleic Acids Res 32, 5800-5808

17. Egger G, Liang G, Aparicio A, Jones PA (2004) Epigenetics in human disease and prospects for epigenetic therapy. Nature 429, 457-463

18. Finnegan EJ (2002) Epialleles-a source of random variation in times of stress. Curr Opin Plant Biol 5, $101-106$

19. Fraga MF, Ballestar E, Paz MF, Ropero S, Setien F, et al. (2005) Epigenetic differences arise during the lifetime of monozygotic twins. Proc Natl Acad Sci USA 102, 10604-10609

20. Gartner K (1990) A third component causing random variability beside environment and genotype. A reason for the limited success of a 30 year long effort to standardize laboratory animals? Lab Anim 24, 71-77

21. Gonzalez E, Kulkarni H, Bolivar H, Mangano A, Sanchez R, et al. (2005) The influence of CCL3L1 gene- containing segmental duplications on HIV-1/AIDS susceptibility. Science 307, 1434-1440

22. Hitchins M, Williams R, Cheong K, Halani N, Lin VA, et al. (2005) MLH1 germline epimutations as a factor in hereditary nonpolyposis colorectal cancer. Gastroenterology 129, 1392-1399

23. Hochedlinger K, Jaenisch R (2002) Nuclear transplantation: lessons from frogs and mice. Curr Opin Cell Biol 14, 741-748

24. Holm TM, Jackson-Grusby L, Brambrink T, Yamada Y, Rideout WM 3rd, et al. (2005) Global loss of imprinting leads to widespread tumorigenesis in adult mice. Cancer Cell 8, 275-285

25. Huxtable SJ, Saker PJ, Haddad L, Walker M, Frayling TM et al. (2000) Analysis of parent-offspring trios provides evidence for linkage and association between the insulin gene and type 2 diabetes mediated exclusively through paternally transmitted class III variable number tandem repeat alleles. Diabetes 49, 126-130

26. Iafrate $\mathrm{AJ}$, Feuk L, Rivera $\mathrm{MN}$, Listewnik $\mathrm{ML}$, Donahoe PK, et al. (2004) Detection of large-scale variation in the human genome. Nat Genet 36, 949-951

27. Jablonka E, Lamb MJ (2005) Evolution in Four Dimensions. (Cambridge, MA: MIT Press)

28. Kaati G, Bygren LO, Edvinsson S (2002) Cardiovascular and diabetes mortality determined by nutrition during parents' and grandparents' slow growth period. Eur J Hum Genet 10, 682-688

29. Kerjean A, Dupont JM, Vasseur C, Le Tessier D, Cuisset L, et al. (2000) Establishment of the paternal methylation imprint of the human H19 and MEST/ PEG1 genes during spermatogenesis. Hum Mol Genet 9, 2183-2187

30. Kruuk LE (2004) Estimating genetic parameters in natural populations using the "animal model." Philos Trans R Soc Lond B Biol Sci 359, 873-890

31. Li E (2002) Chromatin modification and epigenetic reprogramming in mammalian development. Nat Rev Genet 3, 662-673

32. Li E, Bestor TH, Jaenisch R (1992) Targeted mutation of the DNA methyltransferase gene results in embryonic lethality. Cell 69, 915-926

33. Lorincz MC, Schubeler D, Hutchinson SR, Dickerson DR Groudine M (2002) DNA methylation density influences the stability of an epigenetic imprint and Dnmt3a/b-independent de novo methylation. Mol Cell Biol 22, 7572-7580

34. Lumey LH, Stein AD (1997) Offspring birth weights after maternal intrauterine undernutrition: a comparison within sibships. Am J Epidemiol 146, 810-819

35. Mager J, Bartolomei MS (2005) Strategies for dissecting epigenetic mechanisms in the mouse. Nat Genet 37, 1194-1200

36. Martens JH, O’Sullivan RJ, Braunschweig U, Opravil S, Radolf M, et al. (2005) The profile of repeat-associated histone lysine methylation states in the mouse epigenome. EMBO J 24, 800-812

37. McVean GA, Myers SR, Hunt S, Deloukas P, Bentley DR, et al. (2004) The fine-scale structure of 
recombination rate variation in the human genome. Science 304, 581-584

38. Meigs JB, Dupuis J, Herbert AG, Liu C, Wilson PW, et al. (2005) The insulin gene variable number tandem repeat and risk of type 2 diabetes in a population-based sample of families and unrelated men and women. J Clin Endocrinol Metab 90, 1137-1143

39. Mellor J (2005) The dynamics of chromatin remodeling at promoters. Mol Cell 19, 147-157

40. Morgan HD, Sutherland HG, Martin DI, Whitelaw E (1999) Epigenetic inheritance at the agouti locus in the mouse. Nat Genet 23, 314-318

41. Murrell A, Rakyan VK, Beck S (2005) From genome to epigenome. Hum Mol Genet 14 Spec No 1, R3-R10

42. Myers S, Bottolo L, Freeman C, McVean G, Donnelly P (2005) A fine-scale map of recombination rates and hotspots across the human genome. Science 310, $321-324$

43. Newbold RR, Hanson RB, Jefferson WN, Bullock BC, Haseman J, et al. (2000) Proliferative lesions and reproductive tract tumors in male descendants of mice exposed developmentally to diethylstilbestrol. Carcinogenesis 21, 1355-1363

44. Nussey DH, Postma E, Gienapp P, Visser ME (2005) Selection on heritable phenotypic plasticity in a wild bird population. Science 310, 304-306

45. Okano M, Bell DW, Haber DAn, Li E (1999) DNA methyltransferases Dnmt3a and Dnmt3b are essential for de novo methylation and mammalian development. Cell 99, 247-257

46. Pastinen T, Sladek R, Gurd S, Sammak A, Ge B, et al. (2004) A survey of genetic and epigenetic variation affecting human gene expression. Physiol Genomics 16, 184-193

47. Pembrey ME (2002) Time to take epigenetic inheritance seriously. Eur J Hum Genet 10, 669-671

48. Petronis A, Gottesman II, Kan P, Kennedy JL, Basile VS, et al. (2003) Monozygotic twins exhibit numerous epigenetic differences: clues to twin discordance? Schizophr Bull 29, 169-178

49. Pokholok DK, Harbison CT, Levine S, Cole M, Hannett NM, et al. (2005) Genome-wide map of nucleosome acetylation and methylation in yeast. Cell 122, 517-527

50. Rakyan V, Whitelaw E (2003) Transgenerational epigenetic inheritance. Curr Biol 13, R6

51. Rakyan VK, Blewitt ME, Druker R, Preis JI, Whitelaw E (2002) Metastable epialleles in mammals. Trends Genet $18,348-351$

52. Rakyan VK, Chong S, Champ ME, Cuthbert PC, Morgan HD, et al. (2003) Transgenerational inheritance of epigenetic states at the murine Axin $(\mathrm{Fu})$ allele occurs after maternal and paternal transmission. Proc Natl Acad Sci USA 100, 2538-2543

53. Rakyan VK, Hildmann T, Novik KL, Lewin J, Tost J, et al. (2004) DNA methylation profiling of the human major histocompatibility complex: a pilot study for the human epigenome project. PLoS Biol 2, e405

54. Risch NJ (2000) Searching for genetic determinants in the new millennium. Nature 405, 847-856
55. Roemer I, Reik W, Dean W, Klose J (1997) Epigenetic inheritance in the mouse. Curr Biol 7, 277-280

56. Schadt EE, Monks SA, Drake TA, Lusis AJ, Che N, et al. (2003) Genetics of gene expression surveyed in maize, mouse and man. Nature 422, 297-302

57. Schubeler D, MacAlpine DM, Scalzo D, Wirbelauer C, Kooperberg C, et al. (2004) The histone modification pattern of active genes revealed through genome-wide chromatin analysis of a higher eukaryote. Genes Dev $18,1263-1271$

58. Sebat J, Lakshmi B, Troge J, Alexander J, Young J, et al. (2004) Large-scale copy number polymorphism in the human genome. Science 305, 525-528

59. Sharma A, Sharma VK, Horn-Saban S, Lancet D, Ramachandran S, et al. (2005) Assessing natural variations in gene expression in humans by comparing with monozygotic twins using microarrays. Physiol Genomics 21, 117-123

60. Shiao YH, Crawford EB, Anderson LM, Patel P, et al. (2005) Allele-specific germ cell epimutation in the spacer promoter of the $45 \mathrm{~S}$ ribosomal RNA gene after Cr(III) exposure. Toxicol Appl Pharmacol 205, 290-296

61. Shimamura M, Kodaira K, Kenichi H, Ishimoto $Y$, Tamura H, et al. (2002) Comparison of antiandrogenic activities of vinclozolin and D,L-camphorquinone in androgen receptor gene transcription assay in vitro and mouse in utero exposure assay in vivo. Toxicology 174, 97-107

62. Sproul D, Gilbert N, Bickmore WA (2005) The role of chromatin structure in regulating the expression of clustered genes. Nat Rev Genet 6, 775-781

63. Stamatoyannopoulos JA (2004) The genomics of gene expression. Genomics 84, 449-457

64. Suter CM, Martin DI, Ward RL (2004) Germline epimutation of MLH1 in individuals with multiple cancers. Nat Genet 36, 497-501

65. Tuzun E, Sharp AJ, Bailey JA, Kaul R, Morrison VA, et al. (2005) Fine-scale structural variation of the human genome. Nat Genet 37, 727-732

66. Uzumcu M, Suzuki H, Skinner MK (2004) Effect of the anti-androgenic endocrine disruptor vinclozolin on embryonic testis cord formation and postnatal testis development and function. Reprod Toxicol 18, 765-774

67. van De Sluis B, Rothuizen J, Pearson PL, van Oost BA, Wijmenga C (2002) Identification of a new copper metabolism gene by positional cloning in a purebred dog population. Hum Mol Genet 11, 165-173

68. Waterland RA, Jirtle RL (2003) Transposable elements: targets for early nutritional effects on epigenetic gene regulation. Mol Cell Biol 23, 5293-5300

69. Weaver IC, Cervoni N, Champagne FA, D'Alessio AC, Sharma S, et al. (2004) Epigenetic programming by maternal behavior. Nat Neurosci 7, 847-854

70. Weksberg R, Smith AC, Squire J, Sadowski P (2003) Beckwith-Wiedemann syndrome demonstrates a role for epigenetic control of normal development. Hum Mol Genet 12 Spec No 1, R61-R68

71. Wells DN (2005) Animal cloning: problems and prospects. Rev Sci Tech 24, 251-264 
72. Whitelaw E, Martin DI (2001) Retrotransposons as epigenetic mediators of phenotypic variation in mammals. Nat Genet 27, 361-365

73. Wolff GL, Kodell RL, Moore SR, Cooney CA (1998) Maternal epigenetics and methyl supplements affect agouti gene expression in Avy/a mice. FASEB J 12, 949-957

74. Wong AH, Gottesman II, Petronis A (2005) Phenotypic differences in genetically identical organisms: the epigenetic perspective. Hum Mol Genet 14 Spec No 1, $\mathrm{R} 11-\mathrm{R} 18$
75. Xi R, Xie T (2005) Stem cell self-renewal controlled by chromatin remodeling factors. Science 310, 14871489

76. Yan H, Yuan W, Velculescu VE, Vogelstein B, Kinzler KW (2002) Allelic variation in human gene expression. Science 297, 1143

77. Zamore PD, Haley B (2005) Ribo-gnome: the big world of small RNAs. Science 309, 1519-1524

78. Zilberman D, Henikoff S (2005) Epigenetic inheritance in Arabidopsis: selective silence. Curr Opin Genet Dev $15,557-562$ 